\title{
Pig meat quality according to sexual type, feeding system and slaughter weight
}

\author{
B. DESMOULIN *, J.P. GIRARD **, M. BONNEAU *, A. FROUIN *** \\ *I.N.R.A., Station de Recherches sur l'Elevage des Porcs, Saint-Gilles, \\ 35590 L'Hermitage \\ ** I.N.R.A., Station de Recherches sur la Viande, Theix, 63122 Ceyrat \\ **:*: Société Olida et Caby, 50, rue Raspail, 92304 Levallois-Perret
}

France

Feeding systems applied to 72 Large White pigs were optimized according to sexual types using diets based on barley or maizc. The animals were slaughtered at 95 or $115 \mathrm{~kg}$ live weight. Meat was prepared as such (roasts and ribs) or processed according to three methods (cooked hams, dry sausage, dry cured ham). The various products were tested by consumer panels. The main results were the following :

- for pig farmers feeding costs were reduced by the use of cliets based on maize and by slaughter of castrated males at a lower weight than that of females and boars. In the latter, sparing of $36 \mathrm{~kg}$ feed as compared to the castrates was confronted to the possibility of using meat exhibiting sometimes boar taint due to the storage of androstenone in fat,

- muscles showed normal $\mathrm{pH}$ values and water binding capacities; the fat content (especially within muscle fat) and the presence of unsaturated fatty acids in adipose tissue led to large variations in flavour properties.

1) In meat products sexual odours were noticed in $25 \mathrm{p}$. 100 of male meats as soon as the androstenone content exceeded $0.5 \mu \mathrm{g} / \mathrm{g}$. This led to a severe criticism on the flavour and taste of roasts and ribs. Female meats which were leaner and with more unsaturated fat than those of castrates were preferred : the increased unsaturation resulting from the use of maize did not reduce the organoleptic properties of roasts and ribs.

2) Processing of meat did not suppress all sexual odours. In 9 p. 100 of the male meats, androstenone contents exceeding $1.0 \mu \mathrm{g} / \mathrm{g}$ of fatty tissues led to severe criticism concerning cooked hams and to a lesser extent dry products. Meats exhibiting these major sexual odours can be discarded by means of organoleptic analyses and androstenone determinations in the laboratory.

As regards cooked ham preferences (921 judgments) concerned female meats which were leaner and contained more unsaturated fat. In the absence of a marked criticism relative to maize diets, hams from heavier pigs with less hydrated and more mature meats were preferred.

As regards dry sausage preferences (1312 judgements) concerning castrate meats involved pigs with more saturated fats. Conversely, the criticism was more marked on lean female meat with more unsaturated fat.

As regards dry cured ham preferences (701 judgments) concerning castrate meats were emphasized by a very marked criticism on the odour and taste of the products obtained with maize diets. In the lean types (females and entire males) the high slaughter weight improved the organoleptic properties. The higher unsaturation of fat in pigs fed with maize diets was only unfavourable when that meat was used in dry products. On the other hand, the presence of unsaturated fat tended to improve the taste of roasts and ribs or of meats processed by cooking-curing into cooked hams. According to consumer preferences heavier carcasses with more mature meat should be revalorized. 